\title{
Saúde e ambiente na favela: reflexões para uma promoção emancipatória da saúde
}

\author{
Health and environment in the slums: thoughts \\ to foster emancipatory promotion of health
}

\author{
Marcelo Firpo de Souza Porto* \\ Doutor em Engenharia de Produção - UFRJ, Centro de Estudos em Saúde do \\ Trabalhador e Ecologia Humana (CESTEH) da Escola Nacional de Saúde Pública \\ (ENSP) da Fundação Oswaldo Cruz (Fiocruz) Rio de Janeiro/RJ, Brasil.
}

\section{Marize Bastos da Cunha**}

Doutora em Educação — UFF, Departamento de Endemias (Densp) da Escola Nacional de Saúde Pública (Ensp) da Fundação Oswaldo Cruz (Fiocruz) Rio de Janeiro/RJ, Brasil.

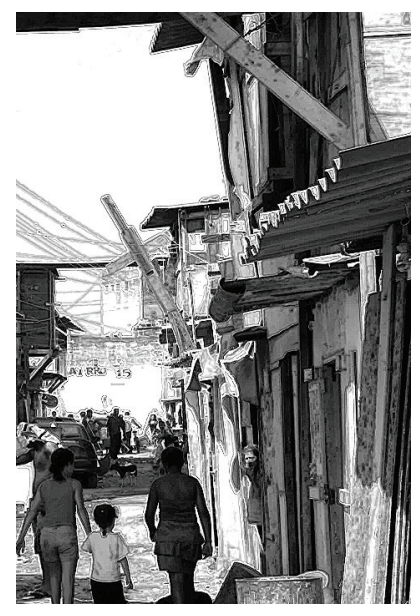

\section{Fatima Pivetta***}

Mestre em Química — PUC Rio, Centro de Estudos em Saúde do Trabalhador e Ecologia Humana (CESTEH) da Escola Nacional de Saúde Pública (Ensp) da Fundação Oswaldo Cruz (Fiocruz) Rio de Janeiro/RJ, Brasil.

\section{Lenira Zancan ${ }^{* * * *}$}

Mestre em Saúde Pública — Fiocruz. Departamento de Ciências Sociais (DCS) da Escola Nacional de Saúde Pública (Ensp) da Fundação Oswaldo Cruz (Fiocruz) Rio de Janeiro/RJ, Brasil.

\section{Jairo Dias de Freitas ${ }^{* * * * *}$}

Doutor em Saúde Pública — Fiocruz. Escola Politécnica de Saúde Joaquim Venâncio (EPSJV) da Fundação Oswaldo Cruz (Fiocruz) Rio de Janeiro/RJ, Brasil.

\footnotetext{
*E-mail: marcelo.firpo@ensp.fiocruz.br.

**E-mail: marizecunha@ensp.fiocruz.br.

***E-mail: pivettaf@ensp.fiocruz.br.

****E-mail: 1enazan@ensp.fiocruz.br.

*****E-mail: jairotek@fiocruz.br.
} 
Resumo: Este artigo discute a relação entre saúde e ambiente em favelas a partir de um projeto de investigação que analisou, por meio de metodologias participativas e de pesquisa-ação, o desenvolvimento de uma política pública (PAC) em três favelas do Rio de Janeiro (Alemão, Rocinha e Manguinhos). Os temas priorizados - moradia e o saneamento - propiciaram levantar três importantes processos reveladores da determinação social da saúde em favelas: o desenraizamento, a provisoriedade e a invisibilidade. Reconhecê-los a partir das vozes dos moradores contribui para o enfrentamento das desigualdades e injustiças por intermédio de uma promoção emancipatória da saúde.

Palavras-chave: Favela. Rio de Janeiro. Promoção da saúde. Moradia. Saneamento.

\begin{abstract}
In this article it is discussed the relationship between health and environment in slums from a research project that analyzed the development of a public policy (PAC - Programa de Aceleração do Crescimento - Growth Acceleration Program) in three slums in Rio de Janeiro (Alemão, Rocinha and Manguinhos) through participative methodology and research-action. The themes that were prioritized - dwelling and sanitation - made it possible to raise three important processes revealing the social determination of health in slums: rootlessness, temporariness and invisibility. To recognize them through the dwellers' voices contributes to face the inequalities and injustice through the emancipatory promotion of health.
\end{abstract}

Keywords: Slum. Rio de Janeiro. Promotion of health. Dwelling. Sanitation.

\title{
1. Introdução: saúde, ambiente e saúde coletiva
}

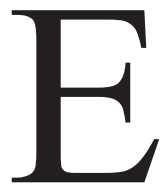

ste artigo pretende discutir a relação entre saúde e ambiente em favelas a partir das experiências acumuladas pelo Laboratório Territorial de Manguinhos (LTM/Fiocruz), em especial a partir do projeto de investigação que buscou analisar, através de metodologias participativas e de pesquisa-ação, o desenvolvimento do PAC em três favelas do Rio de Janeiro.

O LTM nasceu do interesse de juntar ciência e cidadania para transformar realidades urbanas complexas como as favelas, repletas de injustiças sociais e ambientais. Desde 2002, busca o desenvolvimento conceitual e metodológico para uma promoção emancipatória da saúde por meio de práticas de produção compartilhada de conhecimentos que aprofundem questões de saúde, condições de vida, trabalho e meio ambiente, conectando-os com dimensões sociais, políticas e culturais relacionadas às desigualdades sociais, aos déficits de democracia e assimetrias de poder que marcam os territórios urbanos vulneráveis. O espaço privilegiado para a realização da produção compartilhada é o que denominamos de comunidades ampliadas de pesquisa-ação, conformada por fóruns, encontros, oficinas e trabalhos de campo que permitem a confrontação e a integração de perspectivas entre pes- 
quisadores e moradores do lugar na análise e proposição de soluções para problemas socioambientais e de saúde no território, bem como políticas públicas relevantes.

Pensar a favela sob o olhar da saúde e ambiente implica considerar os avanços teórico-metodológicos que essa área tem realizado nos últimos anos no âmbito da saúde coletiva brasileira, em especial na atualização do debate sobre a determinação social da saúde, os processos geradores de desigualdades socioespaciais e sua articulação com movimentos sociais envolvidos em processos de mobilização e resistência. O enfoque socioambiental crítico em construção (Porto, Rocha e Finamore, 2014) tem articulado ecologia e política e aprofunda a análise do fenômeno da globalização e o crescimento do neoextrativismo no chamado Sul Global, incluindo aí países da América Latina, Ásia e África. No caso brasileiro, a intensificação por novos territórios e recursos naturais em setores como o agronegócio, mineração, produção de energia, novas infraestruturas e complexos industriais-portuários resulta em significativos impactos sobre os ecossistemas e a vida das populações vulnerabilizadas nos campos, florestas, águas e cidades.

A construção do enfoque socioambiental crítico dialoga, entre outros, com autores da medicina social latino-americana como Breilh (2006) em sua epidemiologia crítica; da ecologia política (O’Connor 1994; Foster, 2012; Guha e Alier, 2013) e os conceitos de metabolismo social e conflitos ambientais; da geografia política (Porto-Gonçalves, 2006; Haesbaert, 2004) e sua conexão com a geografia da saúde (Monken et al., 2008) e conceitos como território e novas territorialidades; da sociologia ambiental crítica (Acselrad, 2004; Bullard, 2005) que aprofundam a relação entre conflitos ambientais e os movimentos por justiça ambiental; dos estudos pós-coloniais e do grupo denominado Modernidade/Colonialidade (Santos e Meneses, 2010; Mignolo, 2010) por meio de uma epistemologia crítica (ou epistemologias do Sul), que contribuem para a desconstrução de epistemologias hegemônicas da ciência clássica, uma novidade teórica que pode iluminar alguns debates teóricos da saúde coletiva na crítica aos determinantes sociais da saúde (Borde, 2014); além de autores da saúde coletiva, que acumulam experiências de mapeamento de conflitos ambientais (Porto e Pacheco, 2009) e de produção compartilhada de conhecimentos e pesquisa-ação junto com movimentos sociais em lutas pela saúde no campo (Ferreira e Rigotto, 2014; Carneiro et al., 2014) ou nas cidades (Porto et al., 2012).

No âmbito da Associação Brasileira de Saúde Coletiva (Abrasco), dois exemplos recentes de ciência engajada se consubstanciaram na produção do dossiê 
Agrotóxicos, em articulação com a Campanha Nacional contra os Agrotóxicos e pela Vida (Carneiro et al., 2015); e na realização do II Simpósio Brasileiro de Saúde Ambiente (Sibsa) na cidade de Belo Horizonte (MG), entre 9 a 22 de outubro de 2014. O tema central do simpósio foi "Desenvolvimento, conflitos territoriais e saúde: ciência e movimentos sociais para a justiça ambiental nas políticas públicas" com três eixos, sendo um dia dedicado a cada um deles: (1) Desenvolvimento e conflitos territoriais; (2) A função social da ciência, ecologia de saberes e outras experiências de produção compartilhada de conhecimento; (3) Direitos, justiça ambiental e política públicas. Uma importante inovação do evento foi a incorporação de representantes de movimentos sociais na construção da programação do evento e na Comissão Científica, com destaque para o primeiro eixo que abriu o simpósio denominado Fórum de Diálogos de Saberes, organizado por meio de oito oficinas de trabalho. Como revelam as próprias oficinas, os temas relacionados aos povos e territórios dos campos, florestas e águas vêm assumindo maior destaque, embora os temas urbanos sejam de grande relevância demográfica e epidemiológica no Brasil. Ainda que vários temas relacionados à saúde urbana, ao saneamento básico, às doenças transmissíveis (como a dengue), às doenças crônicas e às causas externas (violência e trânsito) tenham amplo destaque, poucos são os trabalhos que aprofundam a determinação social da saúde dentro de um enfoque socioambiental crítico.

Este artigo visa avançar nessa lacuna, discutindo problemas urbanos, com foco nos territórios de favelas, a partir de um enfoque socioambiental crítico tendo por referência os avanços conceituais, metodológicos e empíricos alcançados até o momento pelo Laboratório Territorial de Manguinhos. Para tanto, na próxima seção apresentaremos nossa compreensão da cidade e dos territórios urbanos vulneráveis a partir das contribuições da geografia política, da justiça ambiental e de nossa proposta de construção de uma promoção emancipatória da saúde. Em seguida, discutiremos saúde e ambiente nas favelas a partir das experiências acumuladas no projeto de avaliação participativa do PAC em três territórios de especial relevância no município do Rio de Janeiro: Manguinhos, Alemão e Rocinha. Nosso recorte para discutir saúde e ambiente nas favelas foram a moradia e o saneamento, embora ambos dialoguem com o tema da mobilidade, o qual não aprofundaremos no artigo. Ao final do artigo discutimos as contradições, limites e desafios das políticas públicas nas favelas a partir do reconhecimento de três processos importantes que configuram a experiência do morar em favelas: o desenraizamento, a provisoriedade e a invisibilidade. 


\section{Saúde e ambiente nos territórios na cidade: da zona de sacrifício à promoção emancipatória da saúde}

São inúmeros os desafios das cidades brasileiras em decorrência da forte urbanização, fragmentação territorial e das enormes desigualdades socioespaciais que marcam a vulnerabilidade e os processos de vulnerabilização socioambiental e inúmeros problemas de saúde, um fenômeno latino-americano (Rolnik, 2013). As metrópoles brasileiras expressam um papel contraditório na lógica da acumulação, continuando a marginalizar, apesar das políticas públicas de inclusão social, um amplo conjunto de populações ainda excluídas do trabalho, renda e seguridade social. A isso se acopla a fragilidade histórica das políticas públicas de moradia para as classes populares, o que levou a processos marginais de ocupação irregular que formam vastos territórios, caracterizados como periferias ou favelas, e que emergem como contradição central na tensão entre a cidade formal e informal e os conflitos urbanos (Ferreira, 2007). Ao mesmo tempo, nas cidades e suas periferias também emergem novos movimentos sociais em busca de cidadania e direitos, principalmente através de ações políticas que envolvem a juventude em diversos movimentos culturais, como a literatura, a música e as artes audiovisuais.

Em termos de saúde pública no Brasil, em que pese os avanços no controle da mortalidade infantil e na atenção básica decorrentes da ação do SUS, diversos problemas ainda fazem parte da agenda sanitária de praticamente todas as regiões urbanas do país, assolando mais intensamente as populações vulneráveis dos territórios periféricos. Dentre eles destacamos a falta de saneamento básico, os problemas respiratórios associados à poluição, o consumo de drogas e as mortes por acidentes e violência urbana, além das deficiências do SUS local, em particular de programas como a Estratégia de Saúde da Família. Com efeito, as mudanças que concorrem para a crescente vulnerabilidade social e a ampliação da segregação social têm causado um impacto no padrão de distribuição de doenças em diversas regiões e escalas geográficas. São mudanças que aumentam a complexidade epidemiológica, favorecendo a emergência de novas doenças e a reemergência de antigas endemias. Tal fato se traduz, por exemplo, na projeção que a dengue e a tuberculose vêm assumindo nas metrópoles brasileiras, em particular no município do Rio de Janeiro (Hijjar et al., 2005).

A promoção emancipatória da saúde é uma categoria em construção que tem orientado os trabalhos de atuação do LTM em territórios urbanos vulneráveis. É 
compreendida aqui como um processo dialético voltado para a produção compartilhada de conhecimentos e práticas que favoreçam a constituição de espaços de conquistas de liberdade, de redução de vulnerabilidades socioambientais e de exercício dos direitos humanos fundamentais por intermédio do que Paulo Freire denomina como "inéditos viáveis" (Porto e Pivetta, 2009, p. 220). A produção compartilhada é realizada a partir de dinâmicas de mediação entre os conhecimentos científicos e os saberes populares, contextualizados no cotidiano das populações em seus lugares de vida, considerando assim suas formas de produzir a existência, que se materializam em dispositivos político-pedagógicos para reflexão e ação no território (Zancan et al., 2014). Outra fonte de inspiração do LTM são os movimentos por justiça ambiental, os quais envolvem inúmeras formas de resistência e transformação da sociedade a partir da emergência de problemas e conflitos socioambientais, os quais se realizam em territórios específicos (O’Connor, 2001; Porto e Finamore, 2012). Para o sociólogo norte-americano Robert Bullard (2005), as populações mais discriminadas e pobres tendem a ser confinadas nas áreas mais afetadas pela poluição industrial, falta de infraestruturas e equipamentos sociais, as chamadas "zonas de sacrifício". Essa carga ambiental mais pesada e violenta distribuída de forma desigual em termos socioespaciais é a expressão do racismo ou da injustiça ambiental num dado contexto territorial e populacional, e se materializa em periferias e favelas. Os princípios da promoção emancipatória da saúde e da justiça ambiental implicam não somente relacionar problemas de saúde e ambiente com questões de cidadania, direitos humanos, mas reconhecer as vozes dos moradores e trabalhadores do território como centrais para a transformação social.

A questão da promoção da autonomia é uma das dimensões mais fundamentais ao desenvolvimento da proposta da produção compartilhada de conhecimento. A esse respeito o compartilhamento no processo investigativo é concebido como caminho necessário à construção de um conhecimento crítico, capaz de decifrar a complexidade da realidade e colocar em questão os lugares desses agentes no processo de produção do conhecimento (Cunha, 2007). Os processos de pesquisa e ação inerentes a essa proposta recoloca o papel de sujeitos produtores de conhecimentos e aprendizes em torno da autonomia e confiança em ambos os lados: do pesquisador ou técnico; e do pesquisado-morador ou usuário dos serviços. Busca-se recuperar, dessa forma, o paradigma freireano da educação expresso nas ideias: "Ninguém liberta ninguém, ninguém se liberta sozinho, os homens se libertam em comunhão" (Freire, 2001, p. 27); ou ainda: "Ninguém educa ninguém, ninguém educa a si mesmo, os homens se educam entre si, mediatizados pelo mundo" (Idem, p. 63). 


\section{O PAC em três conjuntos de favelas no Rio de Janeiro}

Como já dito, o Laboratório Territorial de Manguinhos (LTM) da Fiocruz atua desde 2003, produzindo e circulando conhecimentos sobre saúde, ambiente e políticas públicas no conjunto de favelas de Manguinhos (zona norte do município do Rio de Janeiro), tendo como base a construção compartilhada de conhecimento. Em 2012, essa atuação foi ampliada para os Complexos do Alemão e da Rocinha que, tal como Manguinhos, passam por fortes transformações socioespaciais, produzidas pelas intervenções do Programa de Aceleração do Crescimento (PAC) e da Unidade de Polícia Pacificadora (UPP).

Em parceria com a TV Tagarela da Rocinha e o Instituto Raízes em Movimento do Alemão, o LTM desenvolveu então uma pesquisa ${ }^{1}$ que analisou os impactos do PAC Favelas, considerando as intervenções referentes a aspectos socioambientais - particularmente o saneamento e a mobilidade urbana —, seus desdobramentos sobre a ocupação do território e a moradia, o significado para os moradores do viver nesses territórios em mudança, bem como os desdobramentos de tais mudanças sobre a produção social da saúde e da doença.

A investigação procurou elaborar uma visão compreensiva das mudanças nesses territórios, considerando a experiência dos moradores diante dos processos de mudança mais recentes (Thompson, 1981) e os diferentes espaços de pontos de vista dos agentes sociais presentes no mesmo (Bourdieu, 1997). Considerando a referida proposta de produção compartilhada de conhecimento (Marteleto e Valla, 2003; Cunha, 2007) e da pesquisa ação (Brandão, 1985; Thiollent, 1986), a pesquisa desenvolveu-se principalmente através de Comunidades Ampliadas de Pesquisa-ação (CAP) (Porto et al., 2012). Foram constituídas três CAPs (uma em cada território), que reuniram pesquisadores da Fiocruz e moradores dos territórios analisados, inseridos no projeto como bolsistas de pesquisa. Ao longo da pesquisa, as CAPs foram ampliadas com a incorporação de outros moradores, pesquisadores e profissionais, com o objetivo de discutir temas, problemas e alternativas para o território. Por intermédio da CAP foi possível reunir, confrontar e estabelecer diálogos entre distintos saberes e perspectivas, de forma a alcançar maior qualidade, contextualização e transparência tanto para a produção de conhecimento

1. Projeto de pesquisa financiado pelo CNPq (edital MCTI/CNPq/MCIDADES n. 11/2012, Proc. 550285/2012-1) intitulado "Políticas públicas, moradia, saneamento e mobilidade: uma análise participativa do PAC Manguinhos-RJ na perspectiva da promoção da saúde e da justiça ambiental”. 
quanto para os possíveis processos de compreensão e engajamento, principalmente dos moradores, mas também de técnicos e instituições responsáveis pela implementação de políticas públicas.

Além dos encontros sistemáticos das CAPs, o estudo recorreu a um conjunto de procedimentos qualitativos de pesquisa, tendo como base o trabalho de campo, a história oral, o uso de linguagens audiovisuais e a produção compartilhada de conhecimento. Dentre tais procedimentos metodológicos destacamos as oficinas de discussão com atores locais mediadas por materiais do LTM, anteriormente produzidos sobre o PAC Manguinhos, por outros materiais disponibilizados pelos parceiros nos territórios do Alemão e da Rocinha e, ainda, por cadernos, filmetes e imagens produzidas durante a pesquisa. Além de oficinas nos territórios com circulação de cadernos, os materiais produzidos foram disponibilizados no Facebook por meio de uma fan-page denominada Territórios em Movimento e de audiovisuais em um canal do Youtube.

A seguir discutimos alguns dos resultados da pesquisa focados em dois temas importantes para entender as favelas e a determinação social da saúde: a moradia e o saneamento.

\subsection{Moradia e uma nova configuração nas favelas: o novo, sob a forma de maquiagem e 0 antigo, destruído}

Nos três territórios pesquisados destacou-se o fato de que o PAC não atingiu igualmente cada um deles, criando o que podemos denominar como espaços PAC e espaços não PAC, marcando a reprodução das desigualdades socioespaciais em territórios já vulneráveis. Como analisou um morador da Rocinha, "é como se as pessoas fossem criando uma favela dentro da favela [...]. Nos extremos aumenta a pobreza. Que política pública é esta? Que não atende os extremos? Os extremos da favela já eram esquecidos, são esquecidos, vão continuar esquecidos"² (10/8/2013).

2. A fonte dos depoimentos de moradores foram as oficinas de discussão gravadas e filmadas, tendo sido realizadas no Instituto Raízes em Movimento (Alemão), Biblioteca Parque de Manguinhos e TV Tagarela da Rocinha. Indicamos a data da oficina, mas optamos por não identificar os moradores por razões éticas. Os depoimentos foram todos autorizados por meio de Termo de Consentimento Livre e Esclarecido aprovado pelo comitê de ética da ENSP/Fiocruz. 
Algumas áreas que deveriam ser contempladas pelo PAC não o foram, ou o foram de forma precária, como é o caso do Morro dos Mineiros, Matinha e da Travessa Laurinda no Complexo do Alemão. Tais áreas sofreram o impacto de um temporal em dezembro de 2013, durante a execução das obras, que deixou várias famílias sob risco. Em Manguinhos, áreas mais antigas do território, como Vila Turismo e principalmente CHP2 e Parque João Goulart, sofreram intervenções. Mas estas concorreram para desconfigurar tais localidades, fazendo desaparecer ruas e becos, removendo casas e deixando destroços, esgoto a céu aberto e valas no meio do caminho. O resultado é que em Manguinhos tais locais ainda encontram-se mergulhados em um cenário de destruição, experimentando a incerteza quanto às mudanças futuras no território. Há moradores que vivenciam toda essa mudança, angustiados pelo medo de que a localidade vá desaparecer.

Com efeito, o PAC criou uma situação onde não há o novo e o antigo. Há o novo e o destruído (que seria o antigo), sendo que o novo é relatado em todos os três territórios como uma maquiagem. Certamente, a experiência histórica dos moradores diante dos programas públicos anteriores e do jogo eleitoral que sempre os acompanham é uma referência fundamental quando eles avaliam o programa, seja quando o chamam de maquiagem ou quando criticam os efeitos diferenciados em todo o conjunto de favelas, com algumas áreas sendo mais beneficiadas do que outras.

Em Manguinhos, o desencontro entre espaços PAC versus não PAC, ou o novo versus o destruído, é particularmente evidente, inclusive para quem passa pela principal via de Manguinhos, a rua Leopoldo Bulhões, e se arrisca a olhar com mais atenção, para então subir um viaduto em direção ao DSUP, a chamada área nova do território. Referindo-se a todo o complexo construído no DSUP, que, além do conjunto de apartamentos, conta com equipamentos importantes (como uma biblioteca, parque, uma escola de ensino médio, a clínica da família, a UPA), uma moradora destaca: "Este gigante elefante branco, poderia ser um elefantinho menorzinho, se for ali na beira da Leopoldo Bulhões, atende João Goulart, CHP 2, Mandela" (31/8/2013).

Mas, definitivamente, as intervenções que implicaram remoções foram aquelas que mais marcaram a configuração da favela, alterando sua paisagem e sendo experimentada enquanto um drama para os moradores. As grandes construções como o teleférico no Alemão e a elevação da Via Férrea em Manguinhos causaram, e ainda vêm causando, impactos na vida dos moradores. As obras desalojaram várias famílias, mas, além disso, o impacto das máquinas e a remoção de habitações 
abalaram as estruturas de casas que não deviam e não foram removidas. Muitas famílias passaram então a viver sob risco, em casas com paredes fraturadas, tetos e chão cedendo. E a despeito do apelo à defesa civil, em muitos casos com laudos que condenam a habitação, nada foi resolvido.

A remoção, ou sua constante ameaça, faz parte da experiência histórica das favelas, muitas das quais resistiram a ela, como a própria Rocinha. No caso de Manguinhos, ela é parte integrante da história de moradores mais antigos, que já assistiram a muitas remoções, sendo parte do território formado a partir de remoções de outras partes da cidade, com a entrega de moradias provisórias que permaneceram no próprio nome de comunidades como o CHP — Centro de Habitação Provisória. Reflete a provisoriedade e a precariedade de políticas públicas, com promessas jamais cumpridas de entregas de moradias adequadas no futuro. Por outro lado, há moradores de Manguinhos vivendo hoje em várias localidades da cidade, e mesmo do estado, em função das diversas remoções que ocorreram.

$\mathrm{Na}$ Rocinha, as remoções aconteceram de forma injusta, quando comparamos o número de unidades habitacionais oferecidas com as unidades habitacionais construídas, menor que a quantidade de famílias removidas pelas obras do PAC. Da mesma maneira, não foram priorizados os moradores de algumas áreas de risco. Além das remoções, outra forma de expulsão acontece por uma espécie de "gentrificação", ocasionada, principalmente, pelo aumento da especulação imobiliária. A expectativa de melhoria na qualidade de vida na Rocinha vem provocando um aumento dos preços das moradias (aluguel, compra ou venda) e do custo de vida local.

Em Manguinhos e no Alemão ainda não se configurou, de forma tão evidente como a Rocinha, uma situação de "gentrificação", mas é claro que o impacto do PAC junto aos resultados da entrada das unidades de polícia pacificadora (UPP) trouxe mudanças na configuração espacial e social, criando áreas mais privilegiadas e tornando o aluguel e a compra inacessível para muitos moradores. Em Manguinhos, várias famílias removidas precisaram deixar a região e romper seus vínculos com o local, uma vez que não puderam comprar ou alugar uma moradia com a indenização recebida. Por isso, uma moradora de Manguinhos declara: "A gente ainda encontra pessoas peregrinando atrás de casa, seja para aluguel, seja para comprar. Porque não tem mais. Os aluguéis subiram desesperadamente" (31/8/2013). Outro morador também de Manguinhos analisa, comparando a situação de Manguinhos ao que ocorreu na Rocinha: "É que você vai ter uma expulsão, de certa forma, uma expulsão de fato das pessoas que moram nas comunidades pela valorização deste 
espaço. E, como aconteceu na Rocinha e outros lugares, estrangeiros estão comprando as casas, morando na comunidade" (31/8/2013).

O sentido que o PAC vem tendo para a maioria pode ser resumido pela fala de um morador do Alemão: "O novo que chega e nos remove" (20/7/2013). Foi possível concluir que com o PAC o novo que chega remove casas, pequenos negócios e antigos espaços de lazer. O novo desestrutura vias, estratégias de mobilidade e formas de sociabilidade que ajudavam a sobrevivência na favela. Segundo uma moradora de Manguinhos, "quando fala PAC e remoções parece que é coisa nova, mas não é" (31/8/2013). Outra moradora do Complexo do Alemão declara: "O PAC é um Programa de Aceleração do Capitalismo" (20/7/2013). Para muitos, mais uma repetição de projetos que entram sem respeitar os moradores, pois "não foram discutidos, foram apenas apresentados aos moradores", lembra um morador da Rocinha (10/8/2103). O que ficou evidente é que o novo vai destruindo e removendo, sem construir no lugar. $\mathrm{O}$ novo não resolve antigos problemas, com destaque para o saneamento básico que discutiremos a seguir, e ainda cria outros.

\subsection{Provisoriedade e incompletude no saneamento}

É importante destacar o papel do saneamento nos processos saúde-doença nas favelas, concorrendo para as doenças de veiculação hídrica e para sérios agravos da saúde pública, como a tuberculose. Rocinha e Manguinhos são duas das três áreas responsáveis pelos maiores índices da doença no município do Rio de Janeiro. A pesquisa ilustra a importância deste tema, tendo sido possível identificar questões, como falta de planejamento, baixa qualidade e também incompletude das obras nos três territórios. Com efeito, levantamos duas ordens de problemas de saneamento articulados às obras: aqueles que não foram alcançados pela intervenção e aqueles que foram produzidos pelas obras.

$\mathrm{Na}$ Rocinha, as valas continuam convergindo para um antigo valão, que não foi modificado e continua a receber a maior parte do esgoto da favela, transbordando quando as chuvas são intensas. No Centro de Convivência, Comunicação e Cultura (C4) e no Complexo Esportivo, a existência de valas atrapalha a mobilidade de crianças e jovens e constituem fontes de risco para a saúde. A principal mudança na concepção das obras do PAC foi a não incorporação da proposta mais radical do Plano Diretor da Rocinha (Toledo, Silva e Tângari, 2007) prevista inicialmente: liberar e revitalizar os córregos, retirando as moradias insalubres construídas sobre 
os valões para definir uma nova malha de circulação com prédios sendo erguidos nos espaços abertos. Na proposta original, as escadas drenantes e os planos inclinados seguiriam o curso dos córregos nas localidades mais íngremes da comunidade - solucionando em boa parte os problemas de saúde e mobilidade. As novas moradias do Plano previam a não remoção, e sim o deslocamento gradual para as novas casas a ser construídas aproveitando o potencial local, já que a Rocinha cresceu em boa parte ocupada por operários da construção civil que trabalharam na expansão da cidade. Para a decepção de muitos, o projeto de apartamentos e a fábrica de pré-moldados com trabalhadores da própria Rocinha não foram aceitos pelo governo, e as unidades de saúde foram construídas em cima de um valão existente no local.

Em Manguinhos, identificamos os transtornos causados pelas obras do PAC no sistema de saneamento, em particular do Parque João Goulart e CHP2, onde encontramos várias ruas e becos com o esgoto correndo a céu aberto, causando impacto inclusive na mobilidade dos moradores e na situação de saúde do território. Algumas vezes, a passagem dos moradores só era possível porque eles colocavam pedras e pedaços de madeira sobre o esgoto. O nível do esgoto em alguns becos sobe pelo simples gesto de alguém abrir uma torneira ou dar descarga em casa, de forma que o esgoto entra por baixo das casas. Vários moradores relataram comprar água para beber porque a visão cotidiana do esgoto a céu aberto em frente às suas casas tira a pouca confiança na qualidade da água da Cedae, apesar do custo do galão de água pesar no orçamento familiar.

Ainda em Manguinhos, o programa não resolveu nem o problema do saneamento e nem o da drenagem pluvial, considerado prioritário pelos moradores, uma vez que tem implicações diretas sobre as áreas mais baixas do território - CHP2, Parque João Goulart e Vila Turismo. As águas pluviais entram pela rede de esgoto entupindo e fazendo transbordar, muitas vezes rebentando a tubulação. Sem drenagem eficiente, os alagamentos e enchentes são bastante frequentes e intensos nessa parte de Manguinhos. Dessa forma o PAC não resolveu os principais problemas apontados tanto pelos moradores quanto no Plano de Desenvolvimento Urbanístico do Complexo de Manguinhos (PDU), referência para projeto do PAC.

No Alemão, a situação não é diferente, e foram vários os problemas ocasionados pelas obras do PAC. Além do fato de as obras realizadas não atenderam as demandas dos moradores, a precariedade das mesmas é um fato evidenciado em nossas oficinas de discussão. Como analisa uma moradora: "Tem gente que não tem água, tem gente que não tem esgoto. E o PAC passou. O governo não está fazendo manutenção de tudo que ele botou" (20/7/2013). 
Foi por ocasião do já referido temporal que atingiu o Alemão, em dezembro de 2013, que os limites do saneamento ficaram ainda mais evidentes. Os problemas de acesso e manutenção (em especial a precariedade do sistema de esgoto, a falta de drenagem de águas pluviais e o acúmulo de lixo, principalmente depois das obras que deixaram vários entulhos) concorreram para que a forte chuva tivesse um impacto dramático no território, fazendo emergir um dos maiores problemas atuais no Complexo, as moradias em risco (Cunha, 2015).

As dificuldades na manutenção do sistema de água e esgoto nas favelas é um dado histórico, assim como as dificuldades de acesso regular à água em algumas regiões, caso do Alemão e da Rocinha. O PAC não resolveu os problemas de acesso e manutenção, que continuam os mesmos. No entanto, intervenções para ampliar o acesso à água foram realizadas, por exemplo, na Matinha e Morro das Palmeiras, localizadas no Complexo do Alemão, onde foram construídas caixas-d'água. Mas elas estão tendo o mesmo destino de outras construídas em outras épocas no Complexo: não estão em funcionamento. A esse respeito, uma moradora explica: "Uma caixa-d'água que tá lá. Ninguém usa. Uma caixa-d'água enorme [...]. E assim, no primeiro teste da caixa-d'água, os canos estouraram nas casas dos moradores, não aguentou a pressão da água" (20/7/2013).

No acesso e manutenção dos sistemas de água e esgoto, assim como ocorre em algumas outras regiões atingidas por processos de vulnerabilização, o jogo de interesses econômicos e políticos se sobrepõem aos interesses e em prejuízo dos moradores. Talvez seja esse jogo que explique por que o Complexo do Alemão possui várias caixas-d'água, algumas delas desativadas, outras sem operar, e por que as demandas históricas de saneamento por parte dos moradores de favelas não são efetivamente atendidas, conforme os anos passam e os governos mudam.

O fato é que, no âmbito desse jogo político e econômico, para muitos moradores as associações já não os representam, dada sua forte conexão com grupos políticos e econômicos envolvidos em lógicas de clientelismo político acentuadas principalmente em momentos eleitorais. Para outros, há a compreensão de que a não conclusão de obras, especialmente aquelas que envolvem grandes recursos, está associada ao poder das empreiteiras. $\mathrm{O}$ fato é indicado na reflexão de um morador do Alemão:

Uma coisa que eu queria chamar atenção nesta questão de obras não concluídas, e eu não sei se o pessoal percebe muito bem, é esta questão do poder das empreiteiras. Estes contratos que as empreiteiras fazem com o governo. Muitas vezes, as coisas não 
são concluídas porque eles arrumam uma manobra para poder ter mais dinheiro dos cofres públicos, né? [...] é este lance das empreiteiras, porque eles armam. Eu vi isso presente em outra comunidade, lá na zona sul, que a OS armou para cima do governo, ganhou, não concluiu a obra, entrou outra, quando viu a bomba que pegou, pediu quebra de contrato, não quis continuar mais o trabalho [...]. (20/7/2013)

De forma geral, os moradores têm a experiência histórica de uma sucessão de programas que não deram respostas às principais demandas em relação ao saneamento e sabem que há algo errado na dinâmica que articula diferentes interesses, em particular dos governos e dos setores privados. Para alguns tantos, há a clareza de que as empreiteiras dominam o jogo político, com interesses econômicos, com o anúncio de promessas de mudanças sem que efetivamente a situação do saneamento nas favelas mude. Dessa forma, os moradores, referenciados nas suas histórias, vão se aproximando da perspectiva trazida por Eduardo Marques (2000) em seu estudo sobre as intrincadas redes sociais e as relações com o Estado brasileiro, considerando as políticas urbanas, em especial o saneamento no Rio de Janeiro, entre 1975 e 1996. Na rede de relações que liga o Estado às empresas privadas, a dinâmica se efetua de forma a beneficiar a rede, em prejuízo das comunidades, uma vez que os investimentos são descontinuados e as obras são de baixa qualidade, com predominância de práticas de dumping e cartel. $\mathrm{O}$ autor explica que as empresas realizam as partes mais lucrativas dos sistemas e, em seguida, pedem todos os aditamentos possíveis aos contratos, e quando não é mais possível aditar, ameaçam romper o estabelecido, alegando desequilíbrio econômico-financeiro (Marques, 2000). Em parte, essa lógica explica por que a partir de 1994, a despeito dos vultosos investimentos, quase nenhuma favela teve seus sistemas concluídos, com péssima qualidade da maioria das obras físicas e seu caráter incompleto.

Considerando os dados obtidos pela pesquisa, ainda que o PAC tenha se desenvolvido sob uma configuração diferenciada, incluído instâncias diversas dos poderes federal, estadual e municipal, a lógica presente nas intervenções indicou resultados semelhantes ao exposto pela análise de Marques. Foram priorizadas as partes mais lucrativas do sistema, e já há indicações que as obras têm reduzida durabilidade e péssima qualidade, como, por exemplo, o estouro das tubulações de esgoto feitas pelo PAC na Embratel e no Parque João Goulart em Manguinhos.

Para concluir este item, lembramos que saneamento e mobilidade são duas dimensões imbricadas no cotidiano dos moradores, inclusive da cidade formal, já que as ruas são também o espaço das infraestruturas urbanas, tais como esgotamento 
sanitário, águas fluviais, coleta de lixo e distribuição de eletricidade, entre outras. Para quem vive nas favelas, as melhorias nas grandes vias do entorno da favela e nos transportes perdem o impacto se não são acompanhadas de melhorias na mobilidade interna. $\mathrm{E}$ as melhorias na mobilidade interna se remetem de forma geral às condições do sistema de saneamento e pavimentação, e às particularidades do território no que se refere à circulação dos moradores, particularmente nos becos e vielas. Por isso, o saneamento nos três territórios é visto como um problema não resolvido, também como causa de dramas cotidianos, de dificuldades de circulação, e um dos maiores determinantes de problemas de saúde. É muito evidente nos depoimentos dos moradores que qualquer melhoria no território perde o efeito diante da continuidade do esgoto a céu aberto, do acúmulo de lixo, da irregularidade no abastecimento de água e da precariedade da rede de captação de águas pluviais. Nas oficinas, essa discussão apareceu forte na crítica à obra — considerada por muitos como faraônica e não prioritária — do teleférico do Alemão, bem como nos movimentos de resistência à tentativa de implantação do teleférico na Rocinha, sob as palavras de ordem: "Não ao teleférico/Sim ao saneamento". A polêmica aparece na seguinte fala de um morador do Alemão:

Por isso é que eu fiz aquela pergunta: para que serve o teleférico se ainda tem problema de vala negra aberta, se ainda tem problema de mobilidade? Existe uma senhora [...] tem uma filha deficiente. Precisa subir as escadas com a criança nas costas. Para que serve o teleférico, para que serve estes milhões de reais que foram investidos aqui no Alemão se não houve melhoria nenhuma? (20/7/2103).

\section{Desenraizamento, provisoriedade e invisibilidade: desafios das políticas públicas nas favelas}

Analisar questões de saúde e ambiente em favelas no Rio de Janeiro sob a ótica das políticas públicas com foco na moradia e no saneamento revelou um campo profícuo para o aprofundamento da determinação social da saúde e da reprodução das desigualdades socioespaciais em regiões metropolitanas como o Rio de Janeiro.

Ao longo da pesquisa foi discutida pela equipe a existência de certos processos fundamentais para compreender tais territórios em termos de determinação social da saúde e "zonas de sacrifício". São processos desumanizadores, que mostram a 
face mais violenta, dramática e mesmo trágica do modelo de desenvolvimento econômico e social gerador de desigualdades socioambientais, bem como das políticas públicas que lhes têm sustentado: o desenraizamento, a provisoriedade e a invisibilidade.

Dialogando com as reflexões de Eclea Bosi a respeito da obra de Simone Weil (Bosi, 1987 e 2003), o desenraizamento pode ser entendido como o processo que retira o morador de seu lugar por diferentes razões, mas todas relacionadas a um modelo de desenvolvimento econômico e social gerador de desigualdades sociais e ambientais: ele está presente na migração do campo para a cidade, ou quando os moradores precisam deixar suas casas em virtude de uma enchente ou outra situação de risco; ocorre ainda com aqueles que são removidos por causa de programas urbanos que os obrigam a deixar o lugar onde moram. Tais características marcam a formação das favelas no Rio de Janeiro até os dias de hoje.

O desenraizamento contribui para a compreensão do processo de transformação pelo qual passam as populações das favelas e áreas periféricas, que se tornaram estranhas em suas próprias localidades em função da violência vinculada às mudanças na dinâmica do narcotráfico, à ação das milícias e das novas formas de políticas de segurança pública, mediadas por um leque diversificado de agentes sociais, desde $\mathrm{ONG}$ até o narcotráfico. De certa forma, temas relacionados à segurança pública parecem pautar outras intervenções do Estado voltadas para as condições de moradia, saneamento e saúde pública, inclusive o próprio PAC, embora frequentemente de maneira não explícita e fragmentada na prática. Assim como as remoções e o processo de "gentrificação", políticas de segurança pública não cidadãs acabam por dificultar o sentimento de pertencimento tão necessário para o espírito comunitário e as mobilizações de defesa de direitos. Assim, processos em curso de mudança nos territórios da cidade, em vez de promover políticas públicas intersetoriais, contribuir para inserir os moradores na cidade e potencializar suas redes de sociabilidade e coesão social, concorrem para reforçar a provisoriedade como um modo de vida que marca historicamente tais localidades.

A provisoriedade vem sendo apontada como importante marca do surgimento e desenvolvimento das favelas no Rio de Janeiro, em especial das políticas públicas voltadas para elas. Itamar Silva, morador da favela Santa Marta e coordenador do Instituto Brasileiro de Análises Sociais e Econômicas (Ibase), indica que o "Estado sempre teve dificuldade em lidar com o fenômeno das favelas no Rio de Janeiro. A marca desta relação sempre foi a provisoriedade e a incompletude de suas promessas" (Silva, 2011). Desde o surgimento das primeiras favelas em nossa 
cidade, a provisoriedade tem se destacado, especialmente em função das intervenções públicas realizadas de forma provisória, obrigando aos moradores a conviver com a precariedade do que é deixado e a buscar respostas possíveis, muitas vezes criativas e coletivas, para aquilo que fica inacabado. "A provisoriedade no Rio de Janeiro já dura no mínimo 114 anos, e moradores, e moradoras de favelas hoje representam $25 \%$ da população da cidade", diz Itamar Silva.

Por fim, destacamos a invisibilidade. Desde que começaram a se expandir pela cidade, as favelas são consideradas problemas. Por volta de 1920, na primeira campanha contra as favelas na cidade, elas são chamadas de "lepra estética" (Valladares, 2000). A comparação com doenças foi uma forte referência para a nomeação das favelas. No entanto, os modos de vida, as formas culturais, as redes sociais e o cotidiano da favela sempre foram pouco visíveis. Sabemos que, há algumas décadas, o trabalho de muitos profissionais que atuam especialmente nos serviços de saúde e educação, bem como vários estudos e pesquisas, têm permitido tornar esses aspectos mais visíveis. No entanto, ainda há muita invisibilidade em relação ao que acontece no dia a dia das favelas, e em nossa pesquisa identificamos vários problemas produzidos ou agravados pelas obras do PAC. Algumas das possíveis causas de adoecimento e morte nos vários territórios nos revelam que o drama cotidiano dos moradores não é visível, nem para muitos pesquisadores, nem para os profissionais de saúde e assistência social que atuam junto a essas populações, e nem para os sistemas de informações existentes de saúde pública. Não são visíveis também muitas respostas que os moradores têm dado a esses dramas ignorados.

Se o desenraizamento é a marca da experiência histórica de grande parte dos moradores e a provisoriedade é a marca das políticas voltadas para as favelas ao longo da história, dialeticamente a dimensão da permanência e do pertencimento está presente na vida dos moradores, através de suas lutas comunitárias ou mesmo de seus projetos de moradias, construídas em um esforço coletivo e por meio de suas redes de sociabilidade tecidas ao longo dos anos (Cunha, 1995 e 1996). Assim, é preciso considerar que quando uma intervenção como o PAC avança, o faz sob um território marcado pela provisoriedade, mas habitado por moradores que vêm tecendo projetos de vida, suspensos, ou mesmo abortados, pelas incertezas do programa.

O PAC reproduz a incompletude, que marca a história das favelas (Silva, 2011), conforme indica a declaração de uma antiga moradora de Manguinhos: "Então parece que as coisas ficam sempre se refazendo em Manguinhos. Parece que é um passo à frente e outro para trás e não sai do lugar" (23/11/2013). É a 
partir dessa experiência antiga, compartilhada com familiares e vizinhos, que os moradores em todos os territórios avaliam as remoções ocorridas, ou mesmo a ameaça de futuras remoções. E avaliam ainda a mudança para novos apartamentos, muitas vezes percebidos como perda, e não como conquista de um lugar melhor. De acordo com o morador da Rocinha: "Pessoas que já têm ali, duas ou três gerações, estão sendo obrigadas a sair em função de uma política malfeita, mal conversada, que não é oferecida de forma correta para aqueles moradores. Daí, surge um novo grupo de moradores que não tem nenhum vínculo com a criação daquele lugar" $(10 / 8 / 2013)$.

Portanto, é fundamental considerar o impacto das mudanças em territórios marcados por várias intervenções urbanas pontuais e também pela violência. E, particularmente, o impacto na vida das pessoas, compreendendo-o em sua dimensão como experiência coletiva, dramas que se repetem no tempo e no espaço, mas que não assumem visibilidade pública. E que por não serem publicizados, são percebidas como casos pessoais, isolados. Aqui o que está em jogo é a dimensão mais subjetiva desse processo, que se reverte em problemas de saúde e que é timidamente considerada nos programas públicos. Nesse sentido é que pensamos que o avanço efetivo de políticas públicas para as favelas, de forma a integrá-las à cidade, pressupõe o diálogo com essa invisibilidade, de forma que ela possa se manifestar e contribuir na solução dos desafios das políticas públicas para as favelas e para a cidade. Este é um dos sentidos da construção compartilhada de conhecimento e de alternativas aos problemas vividos em nossa cidade.

Recebido em 19/5/2015 - Aprovado em 8/6/2015

\section{Referências bibliográficas}

ACSELRAD, H. Justiça ambiental: ação coletiva e estratégias argumentativas. In: HERCULANO, S.; PÁDUA, J. A. (Orgs.). Justiça ambiental e cidadania. Rio de Janeiro: Relume Dumará, 2004. p. 40-68.

BORDE, E. Notas para uma reinterpretação dos processos de determinação social das iniquidades étnico-raciais em saúde. Tese (Mestrado) — Programa de Pós-Graduação em Saúde Pública, Escola Nacional de Saúde Pública Sergio Arouca, Rio de Janeiro, 2014. 
BOSI, E. O tempo vivo da memória: ensaios de psicologia social. São Paulo: Ateliê Editorial, 2003.

. Lembranças de velhos. 2. ed. São Paulo: T. A. Queiroz/Ed. da Universidade de São Paulo, 1987.

BOURDIEU, P. (Coord.). A miséria do mundo. Petrópolis: Vozes, 1997.

BRANDÃO, Carlos R. Repensando a pesquisa participante. São Paulo: Brasiliense, 1985.

BREILH, J. Epidemiologia crítica: ciência emancipadora e interculturalidade. Rio de Janeiro: Fiocruz, 2006. 317 p.

BULLARD, R. The quest for environmental justice: human rights and the politics of pollution. San Francisco: Sierra Club Books, 2005.

CARNEIRO, F. F. et al. Teias de um observatório para a saúde das populações do campo, da floresta e das águas no Brasil. Tempus: Actas de Saúde Coletiva, Brasília, n. 8, p. 275-293, 2014.

. Dossiê Abrasco: um alerta sobre os impactos dos agrotóxicos na saúde. Rio de Janeiro/São Paulo: EPSJV/Expressão Popular, 2015.

CUNHA, M. B. O desastre cotidiano da favela: reflexões a partir de três casos no Rio de Janeiro. O Social em Questão, Rio de Janeiro, ano XVIII, n. 33, p. 39-58, 2015.

. Testemunhos orais e memória: a formação e a reinvenção da vida no processo de pesquisa em favelas do Rio de Janeiro. In: ENCONTRO REGIONAL SUDESTE DE HISTÓRIA ORAL, 7., Anais..., Rio de Janeiro, 2007.

. Movimentando o binóculo: das análises que imobilizam às falas que interrogam.

In: GARCIA, R. L.; VALLA, V. V. (Orgs.). A fala dos excluídos, Cadernos Cedes, n. 38. Campinas, 1996.

. Grotão, Parque Proletário, Vila Cruzeiro e outras moradas: história e saber nas favelas da Penha. Dissertação (Mestrado) - Programa de Pós-Graduação em Educação, Universidade Federal Fluminense, Niterói, 1995.

FERREIRA, A. A produção do espaço entre dominação e apropriação: um olhar sobre os movimentos sociais. Scripta Nova, revista electrónica de geografía y ciencias sociales, Madrid, v. 11, n. 14, 2007.

FERREIRA, M. J. M.; RIGOTTO, R. M. Contribuições epistemológicas/metodológicas para o fortalecimento de uma (cons)ciência emancipadora. Ciência \& Saúde Coletiva, Rio de Janeiro, v. 19, n. 10, p. 4103-4111, 2014.

FOSTER, J. B. A ecologia da economia política marxista. Lutas Sociais, São Paulo, v. 28, n. 1, p. 87-104, 2012. 
FREIRE, P. Pedagogia do oprimido. São Paulo: Paz e Terra, 2001.

GUHA, R.; ALIER, J. M. Varieties of environmentalism: essays North and South. London: Routledge, 2013.

HAESBAERT, R.; RAMOS, T. O mito da desterritorialização econômica. GEOgraphia, Niterói, v. 6, n. 12, p. 25-48, 2004.

HIJJAR, M. A. et al. Epidemiologia da tuberculose: importância no mundo, no Brasil e no Rio de Janeiro. Pulmão RJ, Rio de Janeiro, v. 14, n. 4, p. 310-314, 2005.

MARQUES, E. C. Estado e redes sociais: permeabilidade e coesão nas políticas urbanas no Rio de Janeiro. São Paulo: Renavam/Fapesp, 2000.

MARTELETO, R.; VALLA, F. Informação e educação popular: o conhecimento social no campo da saúde. Perspectivas em Ciência da Informação, Belo Horizonte, número especial, p. 8-21, jul./dez. 2003.

MIGNOLO, W. Desobediencia epistémica: retórica de la modernidad, lógica de la colonialidad y gramática de la descolonialidad. Buenos Aires: Ediciones del Signo, 2010.

MONKEN, M. et al. O território em saúde: construindo referências para análises em saúde e ambiente. In: MIRANDA, A. C. et al. (Orgs.). Território, ambiente e saúde. Rio de Janeiro: Fiocruz, 2008. p. 23-41.

O'CONNOR, M. Is capitalism sustainable? Political economy and the politics of ecology. New York: Guilfort, 1994. 284 p.

. Causas naturales: ensayos de marxismo ecológico. Cidade do México: Siglo XXI, 2001.

PORTO, M. F. S.; FINAMORE, R. Riscos, saúde e justiça ambiental: o protagonismo das populações atingidas na produção de conhecimento. Ciência \& Saúde Coletiva, Rio de Janeiro, v. 17, n. 6, p. 1493-1501, 2012.

; ROCHA, D. F. Saúde coletiva, território e conflitos ambientais: bases para um enfoque socioambiental crítico. Ciência \& Saúde Coletiva, Rio de Janeiro, v. 19, n. 10, p. 4071-4080, 2014.

; PACHECO, T. Conflitos e injustiça ambiental em saúde no Brasil. Tempus Actas de Saúde Coletiva, Brasília, v. 4, n. 4, p. 26-37, 2009.

; PIVETTA, F. Por uma promoção da saúde emancipatória em territórios urbanos vulneráveis. In: CZERESNIA, Dina; FREITAS, Carlos Machado de. Promoção da saúde: conceitos, reflexões, tendências. Rio de Janeiro: Fiocruz, 2009. p. 207-229. 
PORTO, M. F. S. et al. Produção compartilhada de conhecimento e cidadania: a experiência da comunidade ampliada de pesquisa-ação do Laboratório Territorial de Manguinhos-RJ. In: TOLEDO R. F.; JACOBI, P. R. (Orgs.). A pesquisa-ação na interface da saúde, educação e ambiente: princípios, desafios e experiências interdisciplinares. São Paulo: Annablume, 2012. p. 193-229.

PORTO-GONÇALVES, C. W. A globalização da natureza e a natureza da globalização. Rio de Janeiro: Civilização Brasileira, 2006.

ROLNIK, R. Late neoliberalism: the financialization of homeownership and housing rights. International Journal of Urban and Regional Research, v. 37, n. 3, p. 1058-1066, 2013.

SANTOS, B. S.; MENESES, M. P. Epistemologias do Sul. São Paulo: Cortez, 2010.

SILVA, I. 2011. Favela é cidade (e cidade é favela). Democracia Viva, Rio de Janeiro, n. 47, p. 26-28. Disponível em: <http://www.issuu.com/ibase/docs/dv47/3>. Acesso em: 5 jan. 2015.

TOLEDO, L. C., SILVA, J. M. P. da; TÂNGARI, V. R. Derrubando os muros: planejamento participativo e integração social na comunidade da Rocinha no Rio de Janeiro. In: ENCONTROS NACIONAIS DA ANPUR, 12., Anais..., 2007.

THIOLLENT, M. Metodologia da pesquisa-ação. São Paulo: Cortez/Autores Associados, 1986. (Col. Temas básicos de pesquisa ação).

THOMPSON, E. P. A miséria da teoria. Rio de Janeiro: Zahar, 1981.

VALLADARES, L. P. A gênese da favela carioca: a produção anterior às ciências sociais. Revista Brasileira de Ciências Sociais, São Paulo, v. 15, n. 44, p. 15-2, 2000.

ZANCAN, L. F. et al. Dispositivos de comunicação para a promoção da saúde: reflexões metodológicas a partir do processo de compartilhamento da maleta de trabalho "Reconhecendo Manguinhos”. Interface - Comunicação, Saúde, Educação, Botucatu, v. 18, p. 1313-1326, 2014. 